Dementia

and Geriatric

Cognitive Disorders
Dement Geriatr Cogn Disord 2006;21:403-410

DOI: $\underline{10.1159 / 000092846}$
Accepted: June 9, 2005

Published online: April 25, 2006

\title{
Is Mortality Increased in Mildly Cognitively Impaired Individuals?
}

\author{
A Systematic Literature Review
}

\author{
Uta Guehne Matthias C. Angermeyer Steffi Riedel-Heller
}

Klinik und Poliklinik für Psychiatrie der Universität Leipzig, Leipzig, Germany

\section{Key Words}

Sociodemographic characteristics · Functional

limitation · Mild cognitive impairment $\cdot$ Mortality from 1.0 to 1.9. However, only few studies are available, and a comparison of the literature is problematic, due to variations in criteria and methodology.

Copyright (C) 2006 S. Karger AG, Basel

\begin{abstract}
Numerous studies have focused on the effect of mild cognitive impairment in elderly people. However, the impact of mild cognitive impairment on mortality has rarely been considered so far. This paper reviews recent work on mild cognitive impairment and its mortality risk. Relevant articles were identified by a systematic search of the literature published since 1990 using the databases PubMed, Web of Science and PSYNDEXplus, bibliographies of articles identified and of earlier reviews. Those studies were considered which predominantly included persons aged 65 and over and which relied on population-based samples. Thus only eight studies could be identified. In general, the relative risk (RR) for subjects with mild cognitive impairment according to different concepts in comparison to non-affected persons varies
\end{abstract}

Throughout the paper the designation mild cognitive impairment is used as a generic term for all cognitive changes observed in ageing, since this is the most common usage of the term in the literature. Reference to the specific pre-dementia syndrome of Mild Cognitive Impairment is made clear by using capital letters and the abbreviated form (MCl).
(C) 2006 S. Karger AG, Basel

$1420-8008 / 06 / 0216-0403 \$ 23.50 / 0$

Fax +4161306 1234 E-Mail karger@karger.ch www.karger.com www.karger.com/dem

\section{Introduction}

Since it is known that individuals suffering from mild cognitive impairment are at an increased risk of developing dementia, mild cognitive impairment attracts a great deal of interest from researchers and clinicians. The course of mild cognitive impairment is subject to debate referring to several possible outcomes such as conversion to dementia, subsequent death, stability or even improvement. Most of the studies look at progression to dementia, whereas other outcomes are rarely considered [1].

Studies comparing persons with and without dementia show that moderate and severe cognitive impairment are associated with higher mortality, even after controlling for sociodemographic characteristics, comorbidity, and functional limitation [2-5]. Furthermore, the risk obviously increases with growing severity of the impairment [6]. However, only few is known about the effect on mortality of very mild cognitive impairment, short of dementia.

Population-based studies indicate that the prevalence of mild cognitive impairment is more than double compared to the prevalence of dementia [7]. An average prevalence rate of $3 \%$ to $38 \%$ per annum has been reported 
for people aged 65 and older [8]. Data on the rate of conversion to dementia reported in literature vary greatly, depending on the definition of impairment, sample composition and the length of follow-up. Studies confirm that persons with mild cognitive impairment include a highrisk population for developing dementia [8-10]. This fact also indicates a higher mortality among cognitively impaired persons [11-14], whereas other authors were not able to find significantly higher mortality risk for persons with mild cognitive impairment compared to those without mild cognitive impairment [15].

The present paper gives a review of the literature concerning the following questions: Are mild cognitively impaired individuals at increased risk to die? Beyond, we are trying to find hypotheses explaining factors responsible for a possible association between mild cognitive impairment and increased mortality: is increased mortality solely caused by age or is health in general including mental factors accountable for the greater mortality? Or additionally, is the association between cognitive impairment and mortality related to a possible development of dementia?

\section{Materials and Methods}

Relevant articles on mortality in mild cognitive impairment published since 1990 were identified by searching the databases PubMed, Web of Science and PSYNDEXplus as well as bibliographies of several articles and of earlier reviews [1, 6]. Mortality, death and cognitive impairment as well as terminologies referring to different concepts describing mild cognitive impairment such as Mild Cognitive Impairment (MCI), cognitively impaired, not demented (CIND) or age-associated memory impairment (AAMI) served as keywords. We solely focused on papers which were based on population-based samples (birth cohorts, geographical cohorts or random samples) and applying a prospective study design. Therefore, we did not consider studies with highly selected samples of patients since the possibility of generalizing their results is limited. The major criterion for the inclusion of studies in this review was that they were focusing on explicitly defined concepts of mild cognitive impairment in order to analyze mortality and to improve the comparability of the results. Furthermore, only those English papers were included in which the majority of the examined sample was 65 and older. For those studies not including effect sizes but matching the selection criteria, we calculated, wherever possible, the relative risk based on given data.

\section{Results}

Altogether, only eight studies were found investigating the association between mild cognitive impairment and mortality of which six focused explicitly on the topic. These studies were based on three large population-based samples: the Canadian Study of Health and Aging (CSHA) [11, 15-18], the Kungsholmen Project [10, 19] and the OCTO study [12]. Relevant studies are displayed in detail in table 1, showing different concepts including their definitions and the corresponding mortality risk. In general, the relative risk (RR) for subjects with mild cognitive impairment in comparison to nonaffected persons varies from 1.0 to 1.9 . This means, the probability for cognitively impaired persons to die ranges from a comparable risk at all to a risk that is almost twice as high than that for nonaffected individuals (table 1). Data using the odds ratio $(\mathrm{OR})$ confirm this statement $(\mathrm{OR}=2.0-5.2)$. Looking more closely to the different concepts the following picture emerges.

\section{Mild Cognitive Impairment}

The most widely used concept is that of MCI according to Petersen [20]. MCI criteria include memory complaints, objective memory impairment compared to age and to education-specific norms (1-2 SD), normal general cognitive function, preserved activities of daily living, and absence of dementia [20]. Due to the heterogeneity in the use of the term, three subsets of MCI were proposed: MCI-amnestic focusing on memory loss, MCImultiple domains where several cognitive domains are impaired, and MCI-single non-memory-domain which is characterized by an isolated impairment in a single nonmemory domain [21]. Longitudinal studies of patients with MCI show conversion rates to dementia ranging from $10 \%$ to $30 \%$ annually $[22,23], 20-66 \%$ over $3-4$ years [24-26], and $60.5-100 \%$ over 5-10 years [7]. However, to obtain the highest relative predictive power and best relation of sensitivity and specificity for the onset of dementia all three subsets taken together are required [26]. Although substantial effort was made to define MCI according to generally accepted criteria, this is only partially reflected in the studies reviewed. Unfortunately, the studies use their own categorization which hampers comparability. Frisoni et al. [19] found that in cases of MCI (defined as 1 SD below the mean of age- and educationdefined strata) the mortality risk was significantly higher compared to cognitively unimpaired persons $(\mathrm{OR}=1.8$; $95 \% \mathrm{CI}=1.3-2.5)$. Fisk et al. [15] using CSHA data examined the effects of variations in the MCI case definitions on outcomes. The first subgroup (MCI-1) met all amnestic MCI criteria including subjective memory complaints and intact IADL. Other concepts were modified by the investigators: The second subgroup (MCI-2) required intact IADL performance and the third subgroup (MCI-3) did not include subjective memory complaints. 
Table 1. Literature summary of studies examining the mortality among persons with mild cognitive impairment

\begin{tabular}{|c|c|c|c|c|c|c|c|c|}
\hline Study & $\begin{array}{l}\text { Sample } \\
\text { size }\end{array}$ & Age & $\begin{array}{l}\text { Follow- } \\
\text { up } \\
\text { years }\end{array}$ & $\begin{array}{l}\text { Level of con- } \\
\text { cept/concept/ } \\
\text { subgroups }\end{array}$ & $\begin{array}{l}\text { Risk } \\
(95 \% \mathrm{CI})\end{array}$ & $\begin{array}{l}\text { Risk type, adjusted } \\
\text { for the covariates } \\
\text { mentioned }\end{array}$ & $\mathrm{p}$ value & Criteria used \\
\hline \multicolumn{9}{|c|}{ Mild cognitive impairment } \\
\hline $\begin{array}{l}\text { Frisoni et al. } \\
\text { (2000) [19], Sweden } \\
\text { Kungsholmen Project }\end{array}$ & 1,435 & $75+$ & 3 & $\mathrm{MCI}$ & $1.8(1.3-2.5)$ & $\begin{array}{l}\text { OR: age, } \\
\text { education }\end{array}$ & $<0.001$ & $\begin{array}{l}1 \text { SD below the mean of age- and education-defined } \\
\text { strata }\end{array}$ \\
\hline \multirow{5}{*}{$\begin{array}{l}\text { Fisk et al. } \\
(2003)[15] \\
\text { Canada } \\
\text { Canadian Study of } \\
\text { Health and Aging }\end{array}$} & \multirow[t]{5}{*}{1,790} & \multirow[t]{5}{*}{$65+$} & \multirow[t]{5}{*}{5} & MCI-1 & $1.3(0.6-2.9)$ & \multirow{5}{*}{$\begin{array}{l}\text { RR: age, sex, } \\
\text { education }\end{array}$} & n.s & MCI-1: all amnestic MCI criteria met \\
\hline & & & & MCI-2 & $1.7(0.9-3.3)$ & & n.s & MCI-2: IADL impairment allowed \\
\hline & & & & MCI-3 & $1.3(0.7-2.2)$ & & n.s. & MCI-3: no subjective memory complaints required \\
\hline & & & & MCI-4 & $1.4(0.9-2.3)$ & & n.s. & $\begin{array}{l}\text { MCI-4: neither memory complaints nor intact IADL } \\
\text { required }\end{array}$ \\
\hline & & & & & & & & $\begin{array}{l}\text { Exclusion of subjects whose poor memory test } \\
\text { performance was judged to be related to vascular } \\
\text { cognitive impairment, alcohol abuse, psychiatric illness, } \\
\text { depression, blindness, deafness, or a history of social } \\
\text { isolation }\end{array}$ \\
\hline \multirow{3}{*}{$\begin{array}{l}\text { Hogan et al. } \\
(2000)[11] \\
\text { Canada } \\
\text { Canadian Study of } \\
\text { Health and Aging }\end{array}$} & \multirow[t]{3}{*}{1,782} & \multirow[t]{3}{*}{$65+$} & \multirow[t]{3}{*}{5} & $\begin{array}{l}\text { MCI } \\
(\text { ICD-10- } \\
\text { type 3) }\end{array}$ & $1.4^{1}$ & \multicolumn{2}{|l|}{ RR } & $\begin{array}{l}\text { ICD-10 type } 3 \text { : short- or long-term memory impairment } \\
\text { with a decline in intellectual abilities and personality } \\
\text { change. No functional disabilities }\end{array}$ \\
\hline & & & & $\begin{array}{l}\text { MCI } \\
\text { (DSM-III-R- } \\
\text { type 2) }\end{array}$ & $1.8^{1}$ & & & $\begin{array}{l}\text { DSM-III-R type } 2 \text { : short- and long-term memory } \\
\text { impairment and personality change or impairment in at } \\
\text { least one of the following: abstract thinking, judgement, } \\
\text { higher cortical function. No functional disabilities }\end{array}$ \\
\hline & & & & $\begin{array}{l}\text { MCI } \\
(\text { ICD-10- } \\
\text { type 2) }\end{array}$ & $1.7^{1}$ & & & $\begin{array}{l}\text { ICD-10-type } 2 \text { : short- or long- term memory } \\
\text { impairment with a decline in intellectual abilities; } \\
\text { no functional disabilities }\end{array}$ \\
\hline
\end{tabular}

Cognitive impairment, no dementia (CIND)

$\begin{array}{llll}\begin{array}{l}\text { Ingles et al. } \\ (2003)[16]\end{array} & 1,65965+5 & 1.5(1.2-1.9) & \begin{array}{l}\text { RR: age, sex, }<0.05 \text { exclusion of dementia and presence of some form of } \\ \text { education, index } \\ \text { of comorbidity }\end{array}\end{array}$

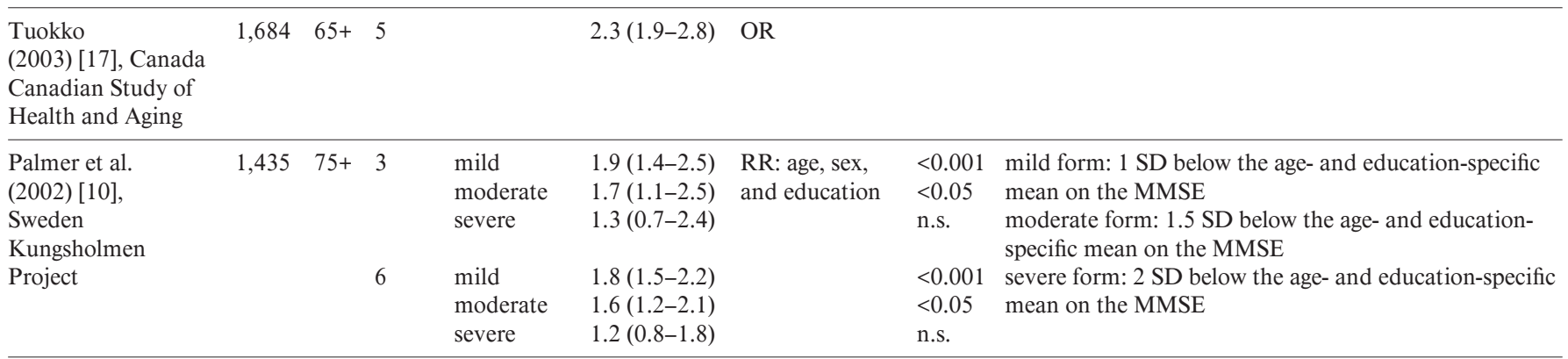

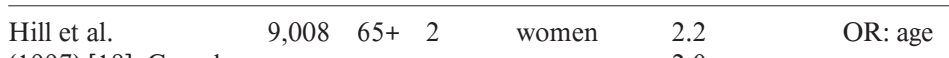

(1997) [18], Canada

Canadian Study of

Health and Aging

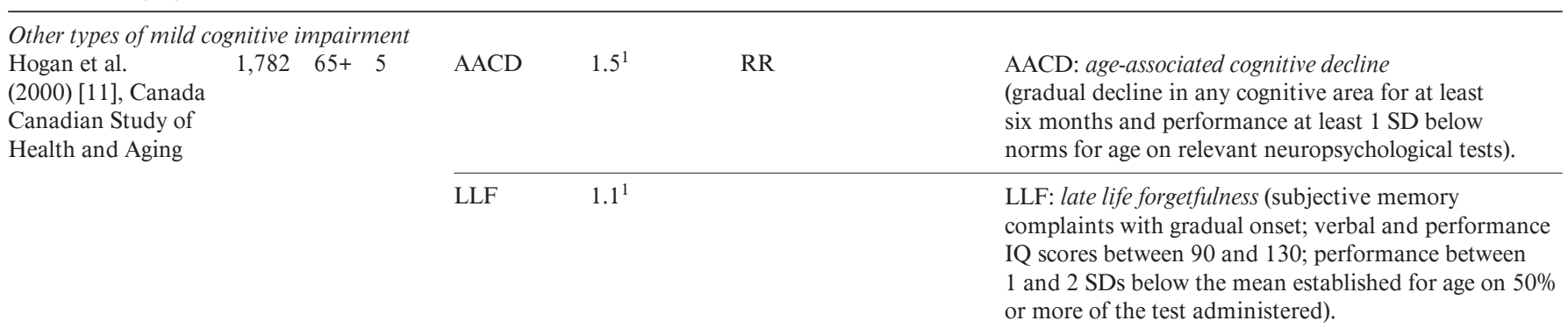


Table 1 (continued)

\begin{tabular}{|c|c|c|c|c|c|c|c|c|}
\hline Study & $\begin{array}{l}\text { Sample } \\
\text { size }\end{array}$ & Age & $\begin{array}{l}\text { Follow- } \\
\text { up } \\
\text { years }\end{array}$ & $\begin{array}{l}\text { Level of con- } \\
\text { cept/concept/ } \\
\text { subgroups }\end{array}$ & $\begin{array}{l}\text { Risk } \\
(95 \% \mathrm{CI})\end{array}$ & $\begin{array}{l}\text { Risk type, adjusted } \\
\text { for the covariates } \\
\text { mentioned }\end{array}$ & $\mathrm{p}$ value & Criteria used \\
\hline & & & & AAMI & $1.2^{1}$ & & & $\begin{array}{l}\text { AAMI: age-associated memory impairment } \\
\text { (subjective memory complaints with gradual onset; } \\
\text { verbal and performance IQ scores between } 90 \text { and 130; } \\
\text { performance at least } 1 \text { SD below the mean established } \\
\text { for young adults on one or more tests) }\end{array}$ \\
\hline & & & & ACMI & $1.0^{1}$ & & & $\begin{array}{l}\text { ACMI: age-consistent memory impairment } \\
\text { (subjective memory complaints with gradual onset; } \\
\text { verbal and performance IQ scores between } 90 \text { and } 130 \text {; } \\
\text { performance within } \pm 1 \text { SD of the mean established for } \\
\text { age on } 75 \% \text { or more of the tests administered) }\end{array}$ \\
\hline $\begin{array}{l}\text { Johansson et al. } \\
\text { (1997) [12], } \\
\text { Sweden, OCTO }\end{array}$ & 204 & $84+$ & $\begin{array}{l}2 \\
4\end{array}$ & $\begin{array}{l}\text { mild } \\
\text { cognitive } \\
\text { dysfunction }\end{array}$ & $\begin{array}{l}3.0(1.5-6.3) \\
5.2(1.8-15.0)\end{array}$ & OR & $<0.01$ & $\begin{array}{l}\text { a rating on cognition }(\mathrm{CR}) \text { represents a composite score } \\
\text { based on the performance across cognitive tests, taking } \\
\text { sensory and motor restrictions into account which } \\
\text { represents a pattern of mild deficit comparable to AAMI }\end{array}$ \\
\hline $\begin{array}{l}\text { Ingles et al. (2003) } \\
\text { [16], Canada } \\
\text { Canadian Study of } \\
\text { Health and Aging }\end{array}$ & 1,659 & $65+$ & 5 & $\begin{array}{l}\text { NP } \\
\text { Dementia }\end{array}$ & $1.6(1.3-2.1)$ & $\begin{array}{l}\text { RR: age, sex, } \\
\text { education, } \\
\text { index of } \\
\text { comorbidity }\end{array}$ & $<0.05$ & $\begin{array}{l}\text { individuals were required to have at least one type of } \\
\text { memory impairment and at least one type of other } \\
\text { cognitive impairment }\end{array}$ \\
\hline
\end{tabular}

$\mathrm{RR}=$ Relative risk OR = odds ratio; IADL = Instrumental Activities of Daily Living; MMSE = Mini-Mental State Examination; n.s. = not significant.

${ }^{1}$ Calculated from data in the paper.

The fourth group (MCI-4) required neither intact IADL nor subjective memory complaints. None of the four MCI subgroups was at significantly increased risk of death $(\mathrm{RR}=1.3-1.7)$ relative to those with no cognitive impairment (NCI) (table 1). Hogan et al. [11] examined data to determine the survival of specific categories of mild cognitive impairment. The criteria used for these categories are summarized in table 1 . Mortality rates differed significantly between groupings $(p=0.002)$ [11] but there was no information about the magnitude of the effect compared to unimpaired persons.

\section{Cognitive Impairment but No Dementia}

The term cognitive impairment, no dementia (CIND) $[27,28]$ classifies all cognitively impaired cases which do not meet the criteria for dementia, and it usually includes persons with impairment caused by medical or psychiatric conditions such as depression, alcoholism, vascular disease and delirium. Subjects with CIND were found to be at a higher risk of dying than unimpaired subjects $(\mathrm{RR}=1.5-1.6)[11,16]$ (table 1$)$. The negative correlation between severity of cognitive impairment and the risk of dying is unexpected but may be due to higher percentages of baseline physical illnesses, such as coronary artery disease, malignancy and cerebrovascular disease, among subjects with mild CIND than among those with severe
CIND [10]. During the time of observation, participants with CIND who survived longer were younger $(p<0.001)$ and in better self-rated health $(\mathrm{p}<0.01)$ compared to those who had died [17]. The mortality risk for men and women with CIND is comparable [18]. It appears that persons with CIND have an increased risk of developing dementia, because individuals diagnosed as CIND progressed to dementia at a rate of $35 \%$ at 3 years' follow-up [10] and at a rate of $42 \%$ over 5 years $[11,16]$.

\section{Other concepts of mild cognitive impairment}

The diagnosis of ageing-associated cognitive decline (AACD) [29] required a decline in any of five broad cognitive domains (memory and learning, attention and concentration, thinking, language and visuospatial functioning) defined as $1 \mathrm{SD}$ below the mean value for the appropriate age and education-matched population. The decline should neither be due to any present or past medical or psychiatric condition, nor to psychoactive substance use, that may cause cerebral dysfunction. The decline should last at least six months in order to decrease the chance of including reversible forms. The conversion rate to dementia by applying AACD criteria was $29 \%$ within 3 years [30] and $47 \%$ within a comparable period (2.6 years) [31]. In tendency, there was also a higher mortality risk for persons who met the criteria of the AACD concept $(\mathrm{RR}=1.5)$ [11]. 
Regarding mortality, significantly unfavorable courses were found for persons with NPDementia [16] and mild cognitive dysfunction [12] compared to unimpaired persons (table 1). To meet criteria for NPDementia (neuropsychological dementia), individuals were required to have at least one type of memory impairment and one type of other cognitive impairment. The diagnosis was only applied to individuals who did not meet the standard DSM-III-R case definition of dementia [16]. $42 \%$ of persons diagnosed as NPDementia developed dementia within 5 years [16]. Individuals not fulfilling DSM-III-R criteria for dementia but having mild impairment in performance on five cognitive tests were rated as having mild cognitive dysfunction [12]. Also a Swedish study by Johansson and Zarit [12] demonstrated that subjects with mild cognitive dysfunction have a 11 times higher risk to progress to dementia over 2 years, and over 4 years, they still have a seven times higher risk to develop dementia compared with cognitively unimpaired controls (patients: $36 \%$, controls: $24 \%$ ).

Comparing the outcomes of all reviewed studies a tendency emerges that concepts that can be used to predict high conversion rates, that is, where, in a closer sense, pre-stages of dementia are recorded, display higher mortality risks compared to unimpaired persons. On the other hand, increasingly neglected concepts - at present, these are the concepts of late-life forgetfulness (LLF) [32], of age-associated memory impairment (AAMI) [33] and of age-consistent memory impairment (ACMI) [32] (table 1) - show no association with a higher mortality risk. Among the group of persons meeting criteria of the AAMI concept, only $9 \%$ had developed dementia within 3.6 years and $7 \%$ within 8 years, respectively $[34,35]$. The AAMI concept is controversial, not least because the performance of elderly is compared with those of younger adults. In addressing the criticism of the original AAMI construct, three different subtypes have been proposed. The term AAMI was retained for the first type, whereas the second type was defined as age-consistent memory impairment (ACMI) and the third as late-life forgetfulness (LLF) [32]. ACMI identifies persons 'whose memories appear to be ageing in accord with normative expectations' and whose memory function is defined by a test performance $1 \mathrm{SD}$ within the age-specific mean on $75 \%$ of applied tests [32]. In contrast, LLF classifies individuals 'whose scores are mildly but quite consistently below average' and whose cognitive functions are defined by a test performance 1-2 SD below age-specific mean on 50\% of applied tests [32]. To our knowledge, currently, there are no epidemiological studies on these two concepts from which one could get information on conversion to dementia.

Unfortunately, the data base appears too small to allow final conclusions on mortality risk in mild cognitive impairment. There are, on the one hand, studies detecting a clear risk of dying compared to unimpaired individuals, on the other hand, there are also studies without such evidence. Yet, there is a tendency that concepts that can predict the development of dementia more reliably also show higher mortality risks. So far, the MCI, CIND and AACD concepts have shown accurate prediction of conversion to dementia as well as a higher mortality. This also holds true for the concepts of mild cognitive dysfunction and NPDementia. Using the criteria of age-associated memory impairment, late-life forgetfulness and ageconsistent memory impairment there is no association with an increased mortality risk.

Since the probability of dying increases with age, it could be assumed that the mortality risk among persons with mild cognitive impairment is also affected by age. Studies included in the present paper adjusting the risk for age also showed an increased mortality risk for persons with any cognitive impairments $[10,16,19]$. On the other hand, Tuokko et al. [17] found that surviving persons with CIND were younger than those who had died $(p>0.01)$.

In order to explain a higher mortality risk among persons with mild cognitive impairment several hypotheses are discussed regarding four fundamental thoughts: (1) increased mortality among persons with mild cognitive impairment could be based on underlying physical illnesses; (2) it could be related to general decline; (3) it could be connected with poorer mental health, or (4) the relation between cognitive impairment and mortality might be associated with dementia. If increased mortality among persons with mild cognitive impairment could be due to underlying physical illnesses, for example, differences in mortality between dead and surviving persons become very likely. It is known and has been proved repeatedly that physical illnesses influence brain function [36-40] and that even forms of mild cognitive impairment are associated with a poor health status $[14,19]$. Based on population-based data, Tuokko et al. [17] showed that after 5 years, survivors of the CIND group were in better self-rated health, which is an important part of reports on general health [41]. Although Frisoni et al. [14] stated that subjective and physical health was generally poorer in the cognitively impaired group they found the effect of cognitive impairment on mortality to be existing but independently of all health factors (coro- 
nary artery disease, cerebrovascular disease, diabetes, malignancy, hip fracture, self-rated health, chronic disease score). Interestingly, already in earlier literature attempts of similar explanation are to be found. Intending to explain different patterns of behavior including cognition, personality and adjustment as well as different psychosocial variables in their relation to survival, the socalled terminal decline theory [42] and the terminal drop theory [43] were developed. 'The general hypothesis states that changes in many functions are not correlated primarily with chronological age as such but instead are related to distance to death' [41]. Terminal decline describes a steady linear decline whereas terminal drop looks more at a curvilinear or accelerated and a considerably shorter course [43]. In earlier studies, a correlation between reduced cognitive performance and distance to death was found over intervals of $3,5,10$ or even more years [ 41 , 44]. On the other hand, according to the terminal drop theory, curvilinear courses become obvious after considerably shorter time, between 3 and 12 months [41]. There is very little known about underlying mechanisms of theses processes but it has been speculated about specific diseases playing a role for the young-old, whereas for the old-old a general decline in health caused by decreased organ reserve capacity might be responsible [41]. Frisoni et al. [14] suggested to consider the so-called psycho-endocrino-immunologic theory [45] as an explanation. Here, psychological variables such as mourning, depression or hopelessness and their effect on endocrine and immunologic parameters are brought into correlation with increased mortality [14]. For instance, the risk to die is higher for persons suffering from negative affects, and further, depressions obviously have an effect on mortality [46]. Arfken et al. [47] investigated the roles of depression and cognitive impairment in predicting 1-year mortality for medically ill adults aged 60 and over. Criteria, like male sex, depression, and more severe cognitive impairment, predicted mortality independent of age, medical illnesses, or disabilities, whereas no connection between cognitive impairment and depression was detected. A fourth hypothesis regarded the association of cognitive impairment with mortality as being affected by dementia. This hypothesis is supported by the facts that mild cognitive impairment is associated with an increased risk of developing dementia $[9,48,49]$, and that survival is less likely among the demented subjects compared to non-demented subjects [6]. Following the assumption that mild cognitive impairment predicts the development of dementia the probability to die should increase. Therefore, concepts of high predictability and high sensitivity as well as specificity regarding conversion to dementia should also predict higher mortality risks. Accordingly, individuals that meet the criteria of concepts with little conversion rates should be at lower risk to die. At present, a verification of this assumption is not possible because the data base is insufficient. However, there is a tendency that concepts predicting the development of dementia more reliably also show higher mortality risks.

\section{Discussion}

At present, there are very few population-based studies examining the mortality risk in correlation with mild cognitive impairment. The studies at hand report an increase of mortality risk which is, however, not always significant. Not all studies were adjusted for age and sex. Due to the variations in methodology and definitions of concepts of mild cognitive impairment a comparison of the findings is problematic and a firm conclusion seems to be impossible. In previous studies the mortality risk among persons suffering from mild cognitive impairment is comparable to or even higher than among persons without such impairment $(\mathrm{RR}=1.0-1.9)$.

Regarding mortality risk in the several concepts, mortality increases particularly among persons meeting the criteria of concepts for which earlier studies gave evidence of high conversion rates towards dementia compared to unimpaired persons. Thus, it can be presumed that a group of people is identified in a pre-stage of dementia. Frisoni et al. [14] are also considering the association of cognitive impairment with mortality might be the same as seen with dementia. 'The plausibility of this hypothesis is supported by the observation that the change of cognitive function over time is a stronger predictor of mortality than is the absolute level of cognitive function' [14]. In order to find a final conclusion concerning this association different concepts of mild cognitive impairment should be operationalized with regard to their original definition, and they should be applied on samples consisting of large numbers of cases. Moreover, it seems decisive to choose narrow observation intervals. For a better explanation of the complexity of mild cognitive impairment and of its course, it seems sensible to examine several outcomes (conversion to dementia, subsequent death, stability or improvement) at the same time.

Further studies are necessary because, without question, the findings are based on a small amount of data. In addition to the assumption above stating that dementia 
could affect the association between mild cognitive impairment and mortality, other hypotheses need to be widely verified in future investigations. It seems plausible that different mechanisms lead to mild cognitive impairment and finally to death. Obviously, changes in cognitive performance are connected to dementia in some persons, whereas for others, a general decline in physiological functions, health and vitality could be decisive. Following the presumption that the phenomenon of mortality in mild cognitive impairment can be explained as a result of different factors, several possible influencing factors should be investigated, not only physical health factors and impairments in ADL/IADL, but also mental health factors, depressive symptoms particularly, as well as subjective health. Other psychosocial factors like level of education, marital status, family biography, social network, for instance, could give helpful information about the mortality among persons with mild cognitive impairment.
Investigating the correlation between mortality and mild cognitive impairment promises to reveal further information about processes accompanying ageing. For the development of differentiated therapeutic strategies considering cognitive changes in persons it is necessary to investigate whether cognitive changes predict development of dementia; whether they are a consequence of fundamental decline in biological functions or, whether they are an effect of depressive episodes.

\section{Acknowledgement}

This work was supported by the Interdisziplinäre Zentrum für Klinische Forschung (IZKF) Leipzig [Interdisciplinary Centre for Clinical Research Leipzig] at the Faculty of Medicine, University of Leipzig (project C07).

\section{References}

1 Palmer K, Fratiglioni L, Winblad B: What is mild cognitive impairment? Variations in definitions and evolution of nondemented persons with cognitive impairment. Acta Neurol Scand Suppl 2003;179:14-20.

$\checkmark 2$ Noale M, Maggi S, Minicuci N, Marzari C, Destro C, Farchi G, Scafato E, Baldereschi M, Di Carlo A, Crepaldi G: Dementia and disability: impact on mortality. The Italian Longitudinal Study of Aging. Dement Geriatr Cogn Disord 2003; 16:7-14.

>3 Helmer C, Joly P, Letenneur L, Commenges D, Dartigues JF: Mortality with dementia: results from a French prospective communitybased cohort. Am J Epidemiol 2001;154:642648.

4 Aguero-Torres H, Fratiglioni L, Guo Z, Viitanen M, Winblad B: Mortality from dementia in advanced age: a 5-year follow-up study of incident dementia cases. J Clin Epidemiol 1999;52:737-743.

5 Ostbye T, Hill G, Steenhuis R: Mortality in elderly Canadians with and without dementia: a 5-year follow-up. Neurology 1999;53:521526.

-6 Dewey ME, Saz P: Dementia, cognitive impairment and mortality in persons aged 65 and over living in the community: a systematic review of the literature. Int J Geriatr Psychiatry 2001; 16:751-761.

7 Morris JC, Storandt M, Miller JP: Mild cognitive impairment represents early-stage Alzheimer disease. Arch Neurol 2001;58:397405 . $\checkmark 8$ Bischkopf J, Busse A, Angermeyer MC: Mild cognitive impairment - a review of prevalence, incidence and outcome according to current approaches. Acta Psychiatr Scand 2002;106: 403-414.

$>9$ Shah S, Tangalos EG, Petersen RC: Mild cognitive impairment. When is it a precursor to Alzheimer's disease? Geriatrics 2000;55:62-68.

10 Palmer K, Wang HX, Backman L, Winblad B, Fratiglioni L: Differential evolution of cognitive impairment in nondemented older persons: results from the Kungsholmen Project. Am J Psychiatry 2002;159:436-442.

11 Hogan DB, Ebly EM: Predicting who will develop dementia in a cohort of Canadian seniors. Can J Neurol Sci 2000;27:18-24.

12 Johansson B, Zarit SH: Early cognitive markers of the incidence of dementia and mortality: a longitudinal population-based study of the oldest old. Int J Geriatr Psychiatry 1997;12: 53-59.

13 Andersen K, Nybo H, Gaist D, Petersen HC, McGue M, Jeune B, Vaupel JW, Christensen $\mathrm{K}$ : Cognitive impairment and mortality among nonagenarians: the Danish 1905 cohort survey. Dement Geriatr Cogn Disord 2002;13: 156-163.

14 Frisoni GB, Fratiglioni L, Fastbom J, Viitanen M, Winblad B: Mortality in nondemented subjects with cognitive impairment: the influence of health-related factors. Am J Epidemiol 1999;150:1031-1044.

15 Fisk JD, Merry HR, Rockwood K: Variations in case definition affect prevalence but not outcomes of mild cognitive impairment. Neurology 2003;61:1179-1184.
16 Ingles JL, Fisk JD, Merry HR, Rockwood K: Five-year outcomes for dementia defined solely by neuropsychological test performance. Neuroepidemiology 2003;22:172-178.

17 Tuokko H, Frerichs R, Graham J, Rockwood K, Kristjansson B, Fisk J, Bergman H, Kozma A, McDowell I: Five-year follow-up of cognitive impairment with no dementia. Arch Neurol 2003;60:577-582.

18 Hill GB, Forbes WF, Lindsay J, McDowell I, Ostbye T: Mortality and cognitive status among elderly Canadians living in the community and in institutions: the Canadian Study of Health and Aging. Can J Publ Health 1997;88: 303-304.

19 Frisoni GB, Fratiglioni L, Fastbom J, Guo Z, Viitanen M, Winblad B: Mild cognitive impairment in the population and physical health: data on 1,435 individuals aged 75 to 95 . J Gerontol [A] 2000;55:322-328.

20 Petersen RC: Mild cognitive impairment: transition between aging and Alzheimer's disease. Neurologia 2000;15:93-101.

21 Petersen RC, Doody R, Kurz A, Moos RC, Morris JC, Rabins PV, Ritchie K, Rossor M, Thal L, Winblad B: Current concepts in mild cognitive impairment. Arch Neurol 2001;58: 1985-1992.

22 Petersen RC, Smith GE, Waring SC, Ivnik RJ, Tangalos EG, Kokmen E: Mild cognitive impairment: clinical characterization and outcome. Arch Neurol 1999;56:303-308. 
-23 Petersen RC, Smith GE, Ivnik RJ, Tangalos EG, Schaid DJ, Thibodeau SN, Kokmen E, Waring SC, Kurland L: Apolipoprotein E status as a predictor of development of Alzheimer's disease in memory-impaired individuals. JAMA 1995;273:1274-1278.

-24 Flicker C, Ferris SH, Reisberg B: Mild cognitive impairment in the elderly: predictors of dementia. Neurology 1991;41:1006-1009.

-25 Kluger A, Ferris SH, Golomb J, Mittelman MS, Reisberg B: Neuropsychological prediction of decline to dementia in nondemented elderly. J Geriatr Psychiatry Neurol 1999;12: 168-179.

-26 Busse A, Bischkopf J, Riedel-Heller SG, Angermeyer MC: Subclassifications for mild cognitive impairment: prevalence and predictive validity. Psychol Med 2003;33:1029-1038.

-27 Ebly EM, Parhad IM, Hogan DB, Fung TS: Prevalence and types of dementia in the very old: results from the Canadian Study of Health and Aging. Neurology 1994;44:1593-1600.

-28 Ebly EM, Hogan DB, Parhad IM: Cognitive impairment in the nondemented elderly. Results from the Canadian Study of Health and Aging. Arch Neurol 1995;52:612-619.

-29 Levy R: Aging-associated cognitive decline. Int Psychogeriatr 1994;6:63-68.

-30 Ritchie K, Artero S: Classification criteria for mild cognitive impairment. A populationbased validation study. Neurology 2001;56: 37-42.

- 31 Busse A, Bischkopf J, Riedel-Heller SG, Angermeyer MC: Mild cognitive impairment: prevalence and predictive validity according to current approaches. Acta Neurol Scand 2003;108: 71-81.

32 Blackford RC, La Rue A: Criteria for diagnosing age-associated memory impairment: proposed improvements from the field. Dev Neuropsychol 1989;5:295-306.
33 Crook TH, Bartus RT, Ferris SH, Whitehouse P, Cohen GD, Gershon S: Age-associated memory impairment: proposed diagnostic criteria and measures of clinical change - report of a National Institute of Mental Health Work Group. Dev Neuropsychol 1986;2:261-276.

34 Hänninen T, Hallikainen M, Koivisto K, Helkala EL, Reinikainen KJ, Soininen H, Mykkanen L, Laakso M, Pyorala K, Riekkinen PJ Sr: A follow-up study of age-associated memory impairment: neuropsychological predictors of dementia. J Am Geriatr Soc 1995; 43:1007-1015.

35 Snowdon J, Lane F: A longitudinal study of age-associated memory impairment. Int $\mathbf{J}$ Geriatr Psychiatry 1994;9:779-787.

36 Haan MN, Mungas DM, Gonzalez HM, Ortiz TA, Acharya A, Jagust WJ: Prevalence of dementia in older Latinos: the influence of type 2 diabetes mellitus, stroke and genetic factors. J Am Geriatr Soc 2003;51:169-177.

>37 Breteler MM, Claus JJ, Grobbee DE, Hofman A: Cardiovascular disease and distribution of cognitive function in elderly people: The Rotterdam Study. BMJ 1994;308:1604-1608. -38 Ferrucci L, Guralnik JM, Salive ME, Pahor M,
Corti MC, Baroni A, Havlik RJ: Cognitive impairment and risk of stroke in the older population. J Am Geriatr Soc 1996;44:237-241.

39 Callahan CM, Hendrie HC, Tierney WM: Documentation and evaluation of cognitive impairment in elderly primary care patients. Ann Intern Med 1995;122:422-429.
40 Lopez OL, Jagust WJ, Dulberg C, Becker JT, DeKosky ST, Fitzpatrick A, Breitner J, Lyketsos C, Jones B, Kawas C, Carlson M, Kuller LH: Risk factors for mild cognitive impairment in the Cardiovascular Health Study Cognition Study. Part 2. Arch Neurol 2003;60: 1394-1399.

41 Berg S: Aging, behavior, and terminal decline; in Birren JE, Schaie KW (eds): Handbook of the Psychology of Aging, ed 4. New York, Academic Press, 1996, pp 323-337.

42 Kleemeier RW: Intellectual changes in the senium. Proc Am Statist Assoc 1962;1:290295.

43 Palmore E, Cleveland W: Aging, terminal decline, and terminal drop. J Gerontol 1976;31: 76-81.

44 Small BJ, Fratiglioni L, von Strauss E, Backman L: Terminal decline and cognitive performance in very old age: does cause of death matter? Psychol Aging 2003; 18:193-202.

45 Ader R, Cohen N, Felten D: Psychoneuroimmunology - interactions between the nervous system and the immune system. Lancet 1995; 345:99-103.

46 Frasure-Smith N, Lesperance F: Depression and other psychological risks following myocardial infarction. Arch Gen Psychiatry 2003; 60:627-636.

47 Arfken CL, Lichtenberg PA, Tancer ME: Cognitive impairment and depression predict mortality in medically ill older adults. J Gerontol [A] 1999;54:152-156.

$>48$ Petersen RC, Smith GE, Waring SC, Ivnik RJ, Kokmen E, Tangelos EG: Aging, memory, and mild cognitive impairment. Int Psychogeriatr 1997;9(suppl 1):65-69.

-49 Petersen RC, Stevens JC, Ganguli M, Tangalos EG: Practice parameter: early detection of dementia: mild cognitive impairment (an evidence-based review). Neurology 2001;56: 1133-1142. 